\title{
PENGELOMPOKKAN KABUPATEN DI PROVINSI BALI BERDASARKAN PERKEMBANGAN FASILITAS PARIWISATA
}

\author{
Nova Sari Barus ${ }^{1}$, I PUtu Eka Nila Kencana ${ }^{2}$, \\ KOMANG GDE SUKARSA ${ }^{3}$ \\ 1,2,3 Jurusan Matematika FMIPA Universitas Udayana, Bukit Jimbaran-Bali \\ e-mail: ${ }^{1}$ novasaribarus@gmail.com, ${ }^{2}$ i.putu.enk@gmail.com, ${ }^{3}$ sukarsakomang@yahoo.com
}

\begin{abstract}
The development of tourism facilities in each district/city between districts with each district is different. The purpose of this study was to determine the grouping of several districts in the province of Bali is based on the number of tourism facilities as well as what the variable identifier of each group. The analysis used in this study is the analysis of clusters and Biplot. The data used is secondary data obtained from the Bali Tourism Office in 2011. Variables used are classified hotel, non-classified hotels, home stays, restaurants, bars, tourist destination, the area of tourism, water tourism and business. The results of this study formed three groups: group 1 Bangli, Buleleng, Jembrana District, Klungkung, Karangasem district and Denpasar City. Group 2 and group 3 Badung district of Gianyar district. Variable identifier is a restaurant for all variables.
\end{abstract}

Keywords: Tourism facilities, Cluster Analysis, District/City in the province of Bali.

\section{Pendahuluan}

Provinsi Bali merupakan salah satu tempat tujuan wisata yang paling banyak dikunjungi oleh wisatawan lokal maupun wisatawan mancanegara. Tercatat pada tahun 2011 sekitar 5.675.121 wisatawan lokal dan 4.646.343 wisata mancanegara yang berkunjung ke Provinsi Bali [1]. Sebagai salah satu daerah tujuan wisata dunia peranan fasilitas pariwisata sangat penting mengingat bahwa perkembangan dunia pariwisata telah mempengaruhi daya tarik, atraksi, fasilitas maupun kegiatan-kegiatan lainnya sehingga perkembangan-perkembangan tersebut perlu disampaikan kepada masyarakat dunia guna menambah informasi. Perkembangan fasilitas pariwisata di setiap daerah tentu saja berbeda. Berdasarkan fakta tersebut dilakukan penelitian sebagai bahan pertimbangan bagi pemerintah untuk mengetahui kabupaten/kota yang mana yang fasilitas pariwisatanya sudah maju dan kabupaten/kota mana yang masih belum memiliki perkembangan atau monoton. Metode analisis yang digunakan untuk penelitian ini adalah Analisis Gerombol dan Biplot.

\footnotetext{
${ }^{1}$ Mahasiswa Jurusan Matematika FMIPA Universitas Udayana

${ }^{2,3}$ Staf Pengajar Jurusan Matematika FMIPA Universitas Udayana
} 
Analisis gerombol digunakan untuk mengelompokkan objek pengamatan berdasarkan karakteristik-karakteristik yang dimiliki (Mahesta, [3]). Analisis kelompok terdiri atas prosedur hierarchi dan non-hierarchi. Salah satu distance adalah dengan menggunakan fungsi jarak Euclidean dimana formulanya sebagai berikut :

$$
\boldsymbol{d}_{r s}=\sqrt{\sum_{\mathrm{k}-\mathbf{1}}^{\mathbf{p}}\left(\mathbf{x}_{\mathrm{rk}}-\mathbf{x}_{\mathrm{sk}}\right)^{2}}
$$

Adapun beberapa algoritma metode agglomerative yang digunakan untuk membentuk kelompok (cluster) adalah single linkage, complete linkage, dan average linkage. Metode pautan tunggal (single linkage) prosedurnya berdasarkan jarak minimum, sedangkan Complete linkage adalah proses clustering yang didasarkan pada jarak terjauh antar obyeknya (maksimum distance). Average linkage adalah proses clustering yang jarak antara dua gerombol didefenisikan sebagai jarak rata-rata antar semua pasangan pengamatan (average distance).

Biplot pertama kali diperkenalkan oleh Gabriel (1971) sehingga sering juga disebut Gabriel's Biplot (Majjtik dan Sumertajaya, [2]). Metode aplikasi dari analisis komponen utama dikembangkan dari bentuk matriks ke dalam peta dua dimensi, sehingga perilaku data mudah dilihat dan diinterpretasikan. Peta tersebut menyajikan plot positif relatif $\mathrm{n}$ objek dengan $\mathrm{t}$ peubah secara simulatan dalam dua dimensi (Majjtik dan Sumertajaya, [2]). Dari analisis ini dapat dikaji positif relatif baik tentang keragamannya maupun korelasinya, serta keterkaitan antara objek-objek dengan peubah-peubahnya.

Biplot merupakan teknik statistik deskriptif ganda yang berdasarkan pada penguraian Nilai Singular (Singular Value Dekomposition/SDV) (Siswadi, dan Budi Raharjo, [4]). Penguraian Nilai Singular (Singular Value Dekomposition) pada suatu matriks $\mathrm{X}$, merupakan suatu teorema dasar yang banyak digunakan dalam perhitungan matriks. Bila terdapat suatu matriks ${ }_{\mathrm{n}} X_{\mathrm{p}}$ yang merupakan matriks berukuran $\mathrm{n} x \mathrm{p}$, maka akan terdapat pula matriks ${ }_{\mathrm{n}} U_{\mathrm{r}}$ yang berukuran $\mathrm{n}$ $\mathrm{x}$ r, matriks ${ }_{\mathrm{r}} L_{\mathrm{r}}$ yang berukuran $\mathrm{r} \times \mathrm{r}$, dan matriks ${ }_{\mathrm{p}} A_{\mathrm{r}}$ yang berukuran $\mathrm{p} \mathrm{x} \mathrm{r}$ (Siswadi, dan Budi Raharjo, [4]).

Dengan demikian matriks ${ }_{\mathrm{n}} X_{\mathrm{p}}$ dapat diuraikan menjadi :

$$
{ }_{\mathrm{n}} \boldsymbol{X}_{\mathrm{p}}={ }_{\mathrm{n}} \boldsymbol{U}_{\mathrm{r}} \mathrm{r}_{\mathrm{r} \mathbf{p}} \boldsymbol{A}
$$

Setelah diperoleh penguraian nilai singular dengan menggunakan persamaan $X=U L A^{\prime}$, matriks $\mathrm{X}$ dapat difaktorkan dalam bentuk sebagai berikut: $\mathrm{X}=\mathrm{GH}^{\prime}$ Dengan $\mathrm{G}$ dan $\mathrm{H}$ merupakan suatu matriks yang masing-masing berukuran $\mathrm{n} \times \mathrm{r}$ dan p x r. Faktorisasi ini dapat ditulis dalam bentuk $X_{i j}=g_{i}{ }^{\prime} h_{j} ; \mathrm{i}=1,2, \ldots, \mathrm{n}$ dan $\mathrm{j}=1,2, \ldots, p$,

Apabila:

$$
X=\left(x_{i j}\right), G=\left[\begin{array}{c}
g_{1} \\
g_{2} \\
\vdots \\
g_{n}
\end{array}\right] \quad H=\left[\begin{array}{c}
h_{1} \\
h_{2} \\
\vdots \\
h_{p}
\end{array}\right]
$$




\section{Metode Penelitian}

Data yang digunakan pada penelitian ini adalah data sekunder yang diperoleh dari Dinas Pariwisata Provinsi Bali tahun 2011. Objek yang digunakan adalah kabupaten/kota yang ada di Provinsi Bali yaitu Kota Denpasar, Kabuapaten Badung, Kabupaten Bangli, Kabupaten Buleleng, Kabupaten Gianyar, Kabupaten Jembrana, Kabupaten Karangasem, kabupaten Klungkung, dan Kabupaten Tabanan. Peubahnya adalah hotel classified, hotel nonclassfied, home stay, restoran, bar, daerah tujuan wisata, kawasan pariwisata, dan uasaha wisata tirta. Langkah-langkah analisis pada penelitian ini adalah:

a. Melakukan analisis gerombol dengan menggunakan sofware SPSS

- Menentukan metode penggerombolan

- Memilih salah satu metode penggabungan

b. Melakukan analisis Biplot

c. Intrepretasi hasil.

\section{Hasil dan Pembahasan}

Jumlah fasilitas pariwisata pada setiap Kabupaten/Kota di Provinsi Bali berdasarkan data yang diperoleh dari Dinas Pariwisata Provinsi Bali 2011.

Table 1. Data Fasilitas Pariwisata Tahun 2011

\begin{tabular}{|l|r|l|r|r|r|r|r|r|}
\hline $\begin{array}{l}\text { Kabupaten/ } \\
\text { kota }\end{array}$ & $\begin{array}{l}\text { classified } \\
\text { hotel }\end{array}$ & $\begin{array}{l}\text { non } \\
\text { classified } \\
\text { hotel }\end{array}$ & $\begin{array}{l}\text { Home } \\
\text { stay }\end{array}$ & Restoran & Bar & $\begin{array}{l}\text { daerah } \\
\text { tujuan } \\
\text { wisata }\end{array}$ & $\begin{array}{l}\text { Kawasan } \\
\text { pariwisata }\end{array}$ & $\begin{array}{l}\text { Usaha } \\
\text { wisata } \\
\text { tirta }\end{array}$ \\
\hline Denpasar & 23 & 191 & 53 & 377 & 93 & 27 & 1 & 94 \\
\hline Badung & 100 & 367 & 168 & 629 & 318 & 35 & 3 & 67 \\
\hline Bangli & 0 & 21 & 8 & 40 & 8 & 61 & 2 & 0 \\
\hline Buleleng & 10 & 115 & 90 & 53 & 30 & 38 & 0 & 0 \\
\hline Gianyar & 16 & 145 & 447 & 242 & 67 & 17 & 1 & 3 \\
\hline Jembrana & 0 & 44 & 18 & 136 & 6 & 15 & 3 & 34 \\
\hline Karangasem & 2 & 29 & 14 & 39 & 10 & 38 & 3 & 13 \\
\hline Klungkung & 7 & 89 & 126 & 95 & 20 & 24 & 1 & 3 \\
\hline Tabanan & 3 & 25 & 92 & 39 & 0 & 15 & 2 & 0 \\
\hline
\end{tabular}

Sumber: Statistik Pariwisata Bali 2011, Dinas Pariwisata Provinsi Bali

\subsection{Analisis Gerombol}

Analisis gerombol digunakan untuk melihat pengelompokan kabupaten/kota yang ada di Provinsi Bali berdasarkan perkembangan fasilitas pariwisatanya. Di dalam analisis gerombol ini teknik yang digunakan adalah berhirarki, dimana metode penggabunganya adalah metode pautan rata-rata. Penglompokan ini akan dianalisa dengan program SPSS 16.0, yang akan disajikan dalam bentuk dendogram. Adapun hasil dari pengelompokan tersebut, dapat dilihat dari diagram pohon (dendogram) pada gambar 1 . 


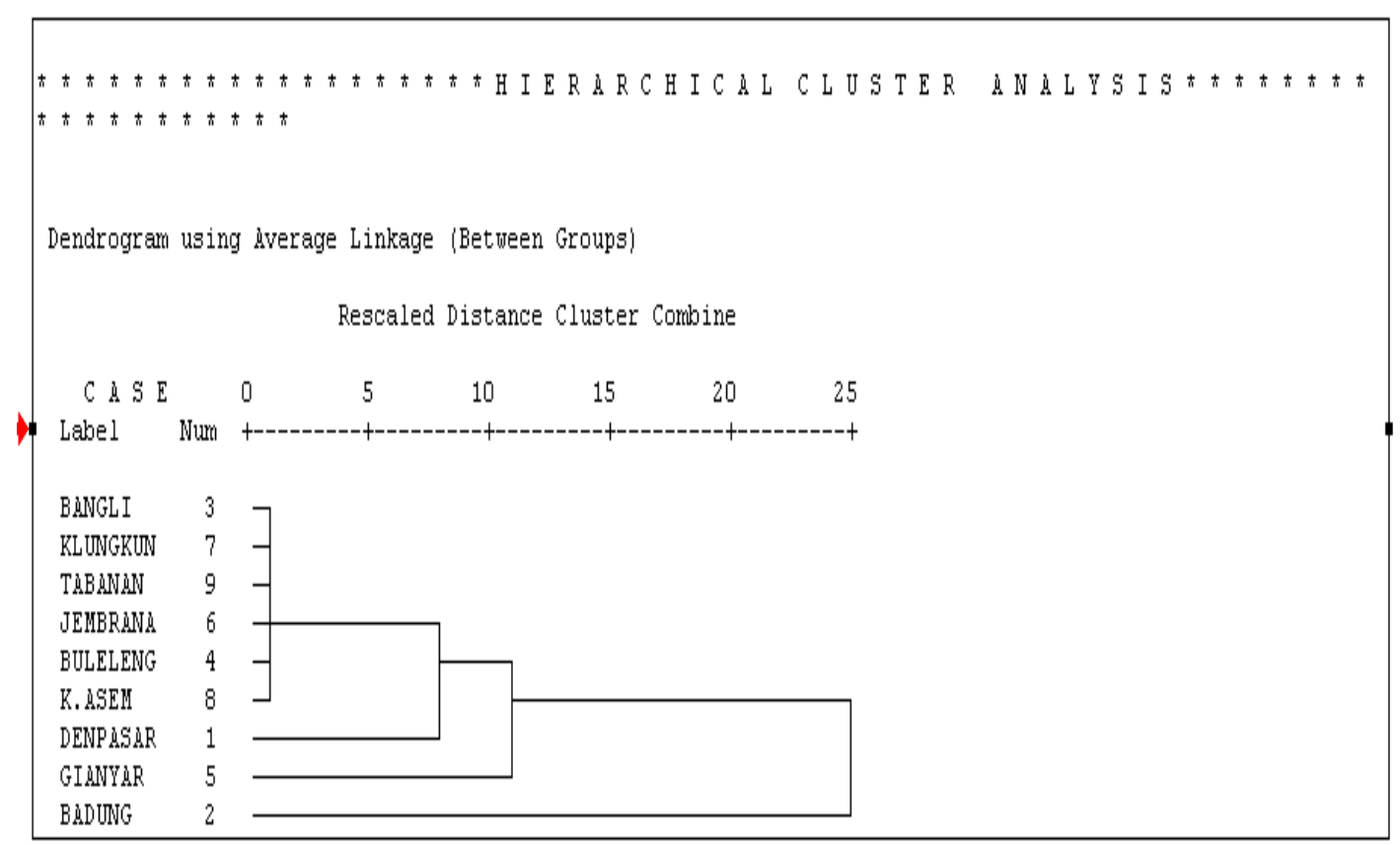

Diolah: Program SSPS 2013

Gambar 1. Diagram Pohon Hasil Analisis Gerombol

Dari hasil analisis gerombol dapat disimpulkan bahwa penggelompokkan fasilitas pariwisata di Provinsi Bali dapat di bagi menjadi tiga kelompok yaitu:

1. Kelompok 1 terdiri dari: Kabupaten Bangli, Kabupaten Buleleng, Kabupaten Jembrana, Kabupaten Klungkung, Kabupaten Karangasem, dan Kota Denpasar.

2. Kelompok 2 terdiri dari: Kabupaten Badung

3. Kelompok 3 terdiri dari: Kabupaten Gianyar

Berdasarkan hasil analisis gerombol terbentuk 3 kelompok, berarti setiap kelompok memiliki perkembangan fasilitas pariwisata yang relatif sama. Analisis gerombol digunakan berdasarkan ukuran kedekatan objek atau kelompok terhadap peubah. Oleh karena itu belum diketahui kelompok yang mana yang memiliki peubah penciri yaitu jenis fasilitas pariwisata yang relatif memiliki perkembangan yang sama, sehingga kelompok-kelompok yang terbentuk dari analisis gerombol akan diplot kembali dengan menggunakan analisis biplot, untuk melihat peubah penciri pada setiap kelompok dan kelompok mana memiliki peubah penciri yang sama. 


\subsection{Analisis Biplot}

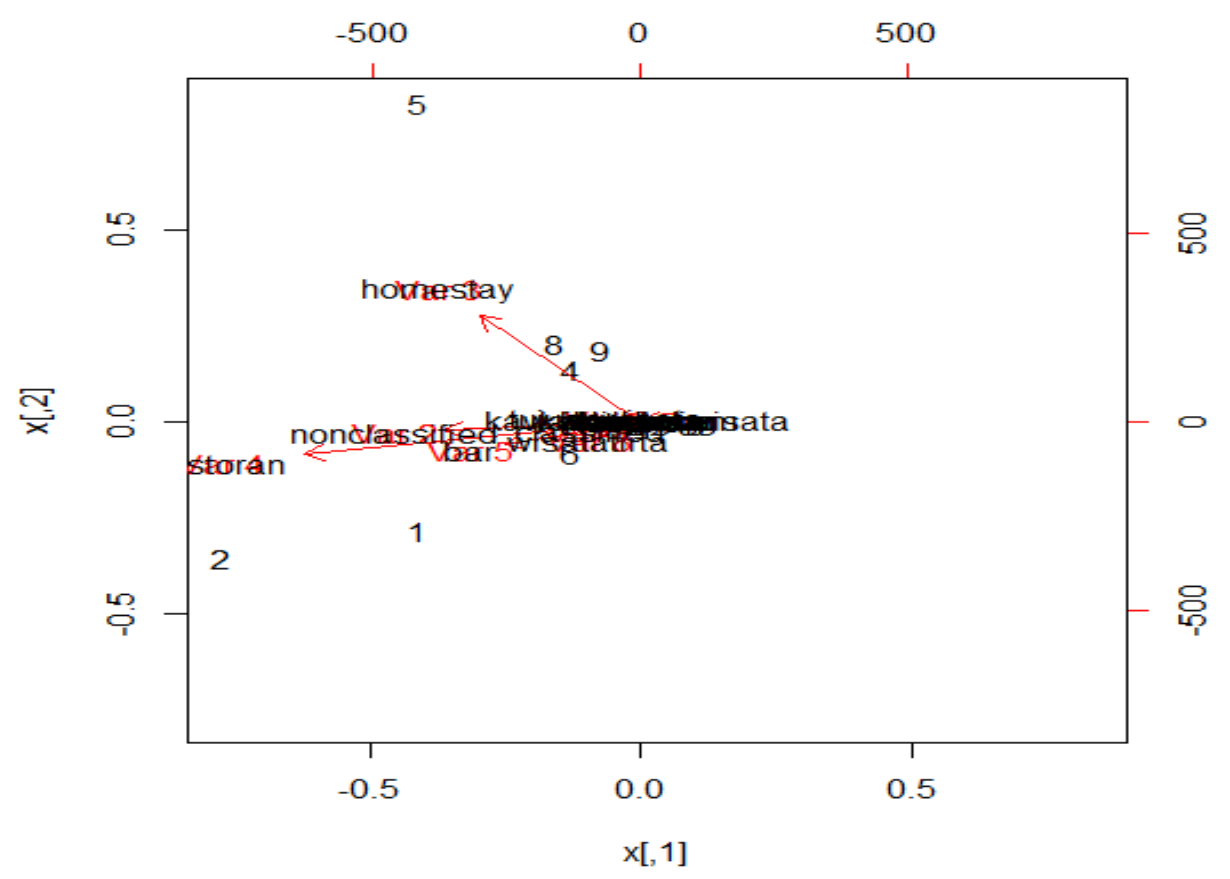

Diolah: Bahasa R 2013

Gambar 2. Plot Hasil Analisis Biplot

Berdasarkan gambar 2, dapat dilihat bahwa restoran yang paling mendekati titik (0,0), selanjutnya ada home stay, hotel nonclassified, bar, hotel classified, usaha wisata tirta, kawasan pariwisata, dan yang paling menjauhi titik $(0,0)$ daerah tujuan wisata. Jika di buat garis dari titik 0,0 maka dapat di lihat bahwa Kota Denpasar dan Kabupaten Badung menjadi satu kelompok sementara Kabupaten Bangli, Kabupaten Buleleng, Kabupaten Gianyar, Kabupaten Jembrana, Kabupaten Karangasem, Kabupaten Klungkung, dan Kabupaten Tabanan.

\section{Kesimpulan}

Berdasarkan hasil analisis gerombol, ditentukan ada tiga kelompok yang terbentuk yaitu:

a. Kelompok 1 terdiri dari: Kabupaten Bangli, Kabupaten Buleleng, Kabupaten Jembrana, Kabupaten Klungkung, Kabupaten Karangasem, dan Kota Denpasar.

b. Kelompok 2 terdiri dari: Kabupaten Badung

c. Kelompok 3 terdiri dari: Kabupaten Gianyar

Peubah penciri dari masing-masing kelompok. Karena kelompok yang terbentuk khususnya kelompok 2 dan 3 hanya memiliki satu anggota kelompok sehingga peubah penciri tidak dilakukan untuk masing-masing kelompok. Peubah penciri untuk setiap objek pada yang paling mendekati ujung vektor peubah yang dilihat dari hasil analisis biplot adalah restoran. 


\section{Daftar Pustaka}

[1] Dinas Pariwisata Provinsi Bali, 2011. Statistik Pariwisata Bali 2011. Denpasar

[2] Majjtik, dan Made Sumertajaya. 2011. Sidik Peubah Ganda dengan Menggunakan SAS. Institut Pertanian Bogor Press. Bogor

[3] Mahesta, Astri. 2010. Penerapan Analisis Biplot dan Gerombol pada pengelompokkan Surat Kabar dan Majalah yang beredar di Kota Denpasar. Skripsi. Jurusan Matematika, FMIPA. Universitas Udayana. Jimbaran.

[4] Siswadi, dan Budi Raharjo.1999. Analisis Explorasi Data Peubah Ganda. Jurusan Matematika. FMIPA. Institut Pertanian Bogor. Bogor 